\title{
International Space Station EVA Operations -Phase 2 Hardware Lessons Learned
}

\author{
David E. Anderson, Debra A. Meyer and Kashyap Shah \\ Boeing Extravehicular \& Crew Systems
}

Copyright (C 2001 Society of Automotive Engineers, Inc.

\begin{abstract}
Phase 2 of International Space Station (ISS) assembly is scheduled to be complete by mid 2001. This paper will describe lessons learned by the hardware providers relative to Extravehicular Activity (EVA) operation for that hardware. With the completion of flight 7A scheduled for June 2001, the space station will include the first set of US solar arrays, $\mathrm{KU}$ band and $S$ band antennas, Laboratory module, Space Station Remote Manipulator System (SSRMS), and Airlock, all EVA assembled. Previously launched hardware will be reconfigured by EVA multiple times to accommodating the changing configuration of the space station to maintain operability. Since the use of EVA is critical to everything from attaching whole segments to installation of external hardware, to reconfiguration of thermal blankets, the EVA operability of this hardware has been an important aspect of the design. Many EVA operations, while well trained for, have not been previously attempted on-orbit. This paper will discuss the hardware lessons learned from completed Phase 2 assembly flights.
\end{abstract}

\section{INTRODUCTION}

The ISS debuted with Flight 2A in December 1998, with two EVA's critical to completion of its mission. Flight $2 A$ set the stage for ISS assembly with EVA operations playing a critical role in assembly in stark contrast to the assembly of the Mir space station. 9 EVA's in 2000 tied the shuttle record for most US EVA's in a given year and greatly advanced ISS to the largest and most powerful spacecraft ever (Reference 1). Throughout the assembly, EVA capability both enabled mission success and defined it. 2001. The EVA Rate doubles in 2001 and redoubles in 2002 (see Figure 1). In addition to the obvious efficiencies required to support training and execution of this wall of EVA, it is also critical to feed forward lessons learned in refining EVA operable hardware to reduce risk and cost.

This paper is intended to capture lessons learned at a hardware provider level for the ISS assembly flights

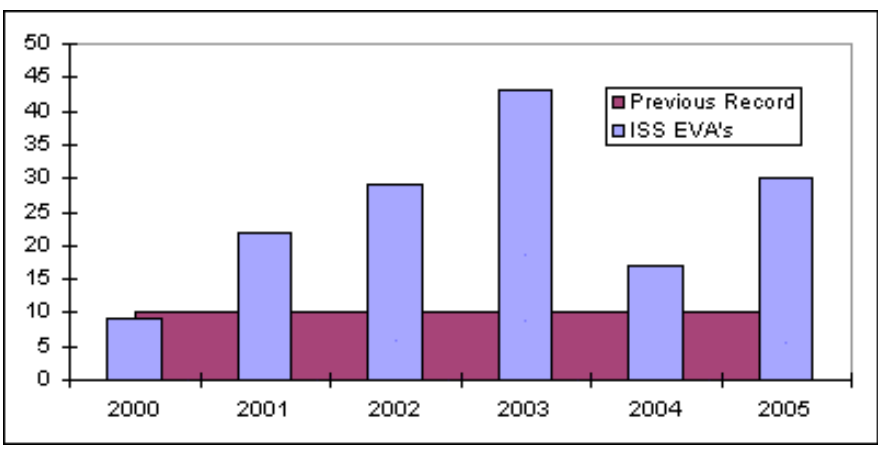

Figure 1. ISS Assembly EVA's per year (Reference 3)

completed to date (see Figure 2), as seen from the Boeing Huntington Beach Engineering Mission Support Room. This is only one piece of a larger, comprehensive summary of the lessons learned by NASA's EVA team in total, which continues to be written. The hardware flown thus far have been designed and verified to a set of general EVA requirements (see Reference 2). In different ways, each of the ISS assembly flights has expanded our understanding of EVA operability beyond the black and white requirements ISS was designed to.

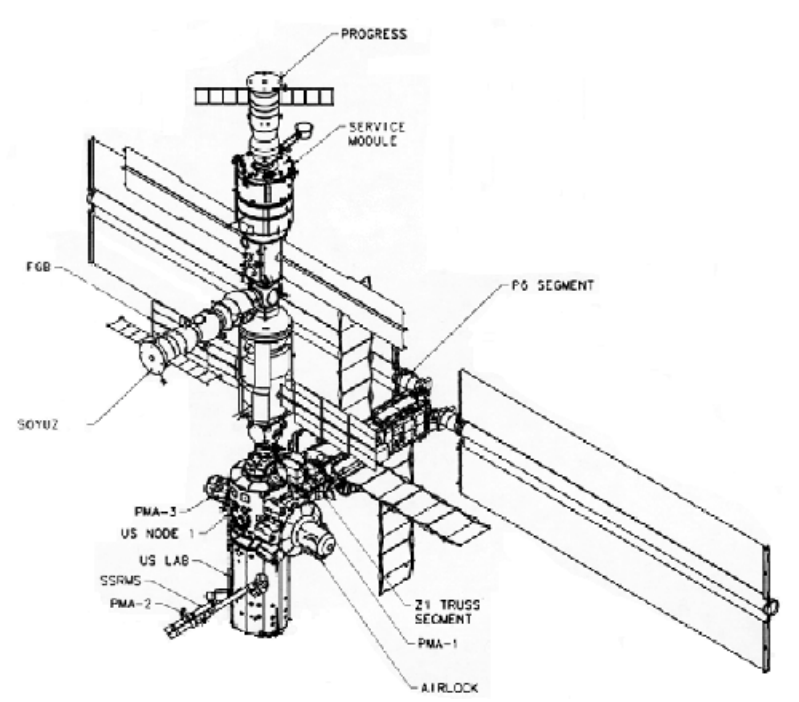

Figure 2. ISS at the completion of flight $7 \mathrm{~A}$. 


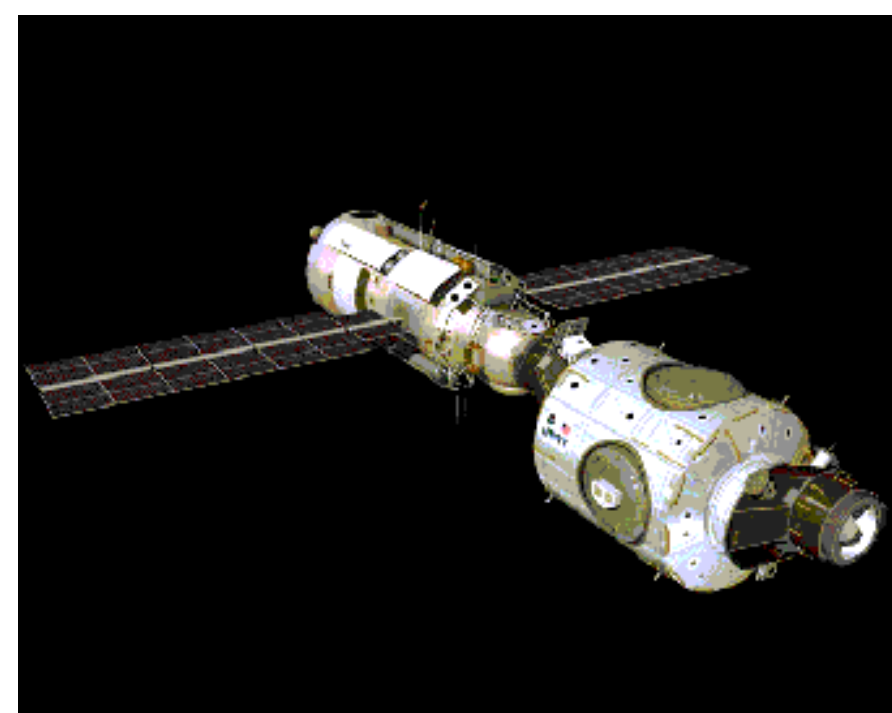

Figure 3. ISS Configuration during Flights $2 \mathrm{~A}, 2 \mathrm{~A} .1$ and $2 \mathrm{~A} .2 \mathrm{~A}$

We hope to capture some of these poignant events in this paper.

\section{FLIGHT 2A NODE 1}

STS-88 lifted off on December 4, 1998 with a crew of six astronauts. The mission was a total of eleven days, including 6 docked days with three EVA days. Flight $2 \mathrm{~A}$ is the second of a series of flights intended to construct the Space Station over a four and a half year period. The designation " $A$ " refers to the fact that it is an American launch.

Flight 2A operations extend from Orbiter launch, through mated Orbiter-Station operations, and conclude with Stage 2 deployment. These cover payload preparation activities, Station and Orbiter system checkout Orbiter rendezvous and docking, Station assembly, subsystem activation and checkout and Orbiter departure operations. Assembly flight $2 \mathrm{~A}$ launches the cargo element, which includes Node 1 and Pressurized Mating Adapters (PMA) 1 and 2. These 3 elements are preintegrated on the ground. They are then launched and attached to the Space Station as one single cargo element (See Figure 3).

Node 1 is a pressurized, environmentally controlled element. It provides an intersection between the other pressurized elements. This intersection will be used to provide an environment for transporting people, equipment and utilities for long-duration crew operations and activities. This node houses the supporting utility systems and other accommodations to facilitate such transfers. Node 1 also contains a storage rack of prepositioned critical spare EVA tools.

PMA-1 is located on the rack end of Node 1 toward the forward Orbiter payload bay. The PMAs are attached to Node 1 axial ports by Common Berthing Mechanisms (CBMs). PMA-1 functions as a pressurized passageway
Table 1. Summary of EVA on STS-88 Flight 2A

\begin{tabular}{|c|c|}
\hline EVA1 & $\begin{array}{l}\text { - Crew members made all umbilical } \\
\text { connections necessary to activate Node } \\
\text { 1. Upon completion of the first EVA the } \\
\text { ground sent commands to the Node to } \\
\text { confirm power and activation. }\end{array}$ \\
\hline EVA2 & $\begin{array}{l}\text { - Installation of EVA translation aids and } \\
\text { tools (handrails and foot restraint } \\
\text { sockets), installation of the early } \\
\text { communications (ECOMM) system } \\
\text { antennas, and routing of the } \\
\text { communications cable from the } \\
\text { Functional Cargo Block (FGB) to the } \\
\text { starboard antenna }\end{array}$ \\
\hline EVA3 & $\begin{array}{l}\text { - To support objectives of downstream } \\
\text { assembly missions. Tasks included } \\
\text { installation of a large tool bag for storing } \\
\text { EVA tools outside the station and } \\
\text { repositioning of foot restraints. } \\
\text { Additionally, the two crewmembers } \\
\text { disconnected the umbilical on PMA-2 so } \\
\text { that PMA-2 can be relocated in the } \\
\text { future. Ingress of the Node } 1 \text { and FGB to } \\
\text { install ECOMM system equipment and } \\
\text { transfer stowage items took place } \\
\text { between the second and third EVA's, on } \\
\text { Flight Day } 8 \text {. Following the completion of } \\
\text { the three EVA's and Node } 1 \text { and FGB } \\
\text { ingress activities, the orbiter undocked } \\
\text { from the ISS. }\end{array}$ \\
\hline
\end{tabular}

(for crew, equipment and supplies) between Node 1 and the Functional Cargo Block (FGB). PMA-2 is located on the forward axial port end of Node 1 toward the Orbiter aft payload bay. The PMAs are attached to Node 1 axial ports by Common Berthing Mechanisms (CBMs). PMA-2 functions as a pressurized docking interface between the Orbiter and Station. The main objectives of the one scheduled EVA are shown in Table 1.

The PMA2-to-Node cables lay across the Node forward end cone after they were deployed. They had to be routed across the end cone to avoid covering the Space Vision System (SVS) targets also on the end cone. This was worked on the ground with the EVA crew with photos taken of the area near the connectors and across the end cone. No photos were taken of the remainder of the cables back to their points of origin on the PMA. On orbit, the cables did not behave the same, and were routed differently across the PMA prior to reaching the end cone. A target was partially covered and a subsequent flight required EVA effort to clear the target. Detailed photos of the entire desired configuration/EVA workarounds practiced on the ground would have been useful if taken. 
The Node trunnion covers had late revisions made to them prior to launch. However, the parts were not updated with the revised drawing letter. The covers were manifested in the mid-deck locker and were installed on orbit. There was a right hand left hand configuration of the covers but only two were revised. However, all covers had the same rev letter. During the mid-deck locker bench review, the revision letters of the hardware needed to be confirmed against the drawing numbers. The two altered covers were supposed to go in specific locations but it was not immediately apparent which covers went in which locations. The bottom line is that the covers were installed successfully, but not without delays and the crew just waiting while ground confirmed which covers went in which locations. The crew had to have descriptions of which cover went in each location. Thus, the need for confirmation of part number revision letters to latest revision of drawings for hardware to be assembled/operated on orbit was needed.

Also, the CETA lights that are launched on $8 \mathrm{~A}$ but installed on the Node on orbit were never fit checked for $2 \mathrm{~A}$ because they are not launched until 8A. It was thought that $8 \mathrm{~A}$ is so far away that attaching the CETA lights to the Node was not a priority task. As a result, fit checks/EVA tests of were performed on the pad. That was the first chance there was proper access to perform the fit checks. Some people wanted to scrub the checks because the hardware wasn't "2A" hardware. When the fit checks were performed, the light booms would not seat in their receptacles on the Node due to some mounting bolts. The heads of the bolts stuck out and caused interference in the soft dock position. They would not have mated on orbit and there was no on orbit workaround for this. When they were launched, they would've needed to be stowed or brought back home. The lesson learned here is always fit check when possible.

\section{FLIGHT 2A.1 ISS SPACEHAB LOGISTICS}

STS-96 lifted off on May 27, 1999 with a crew of seven astronauts. The mission was a total of nine days, including 5 docked days with two EVA days.

During Flight Day 4, STS-96 Astronauts Tammy Jernigan and Dan Barry transferred and installed two cranes from the shuttle's payload bay to locations on the outside of the station. They also installed two new portable foot restraints that will fit both American and Russian space boots, and attached three bags filled with tools and handrails that will be used during future assembly operations.

Once those primary tasks were accomplished, Jernigan and Barry installed an insulating cover on a trunnion pin on the Unity module, documented painted surfaces on both the Unity and Zarya modules, and inspected one of two early communications system antennas on the Unity.
Other tasks completed during the space walk included moving foot restraints into PMA-1 and installing three bags containing tools for use during later flights.

Throughout the space walk, Jernigan and Barry were assisted by their crew mates as Mission Specialist Ellen Ochoa operated the Shuttle's robot arm to maneuver Jernigan around Discovery's cargo bay, and Canadian Space Agency astronaut Julie Payette acted as "choreographer" of the space walk from Discovery's flight deck.

Table 2. Summary of EVA on STS-101 Flight 2A.2A

\begin{tabular}{|l|l|}
\hline EVA1 & $\begin{array}{l}\text { Inspect \& re-install OTD (Orbit } \\
\text { Replaceable Unit (ORU) Transfer } \\
\text { Device) to accomplish a hard dock } \\
\text { configuration. }\end{array}$ \\
- Install the final parts of the STRELA \\
crane on the PMA1. \\
$\begin{array}{l}\text { Remove and replace port ECOMM } \\
\text { system antenna due to degraded } \\
\text { performance. } \\
\text { Install handrails on Unity in support of } \\
\text { future Z1 berthing flight (Flight 3A). } \\
\text { Clear Space Vision System (SVS) target } \\
\text { to support future 3A docking. } \\
\text { Install centerline camera cable to support } \\
\text { future 5A docking. }\end{array}$ \\
\hline
\end{tabular}

Sunday's extravehicular activities culminated in the second longest space walk in shuttle history lasting 7 hours, 55 minutes. The 45th space walk in space shuttle history and the fourth of the International Space Station era - began at 9:56 p.m. Central time Saturday night, and concluded at 5:51 a.m. Sunday morning. All of the objectives mapped out for this excursion, including a couple of unscheduled activities were accomplished.

The excursion raised the total number of International Space Station era space walks to four, with the total time spent on construction activities now standing at 29 hours, 17 minutes. Together, STS-88 Astronauts Jerry Ross and Jim Newman spent a total of 21 hours, 22 minutes outside Endeavor during their three space walks.

\section{FLIGHT 2A.2A SPACEHAB LOGISTICS}

STS-101 lifted off on May 19,2000 at with a crew of seven. The mission was a total of ten days, including 6 docked days with one EVA day. The Space Station consisted of the Russian FGB and the US Node Unity (See Figure 3). The shuttle docked to PMA2. The main objectives of the overall flight were to perform FGB refurbishment (install four new batteries, ten new smoke detectors, and four new cooling fans) to extend FGB lifetime and to prepare the station for the arrival of the Russian built Zvezda Service Module. The main 
objectives of the one scheduled EVA are shown in Table 2.

During the EVA, a crewmember could not install a on orbit installed handrail $(\mathrm{OIH})$ in the number 8 position of Node 1 due to lack of sufficient clearance with co-located cabling. Research on the ground showed that this handrail did not fit in ground fit checks either, but that the installation had been added to the EVA without properly confirming the EVA checklist with the fit check data. The crew was advised to install the handrail in a position slightly above the planned position, which still maintained the functionality. As a result of this incident, subsequent flights have included more comprehensive procedures to assure fit check data is confirmed before an installation

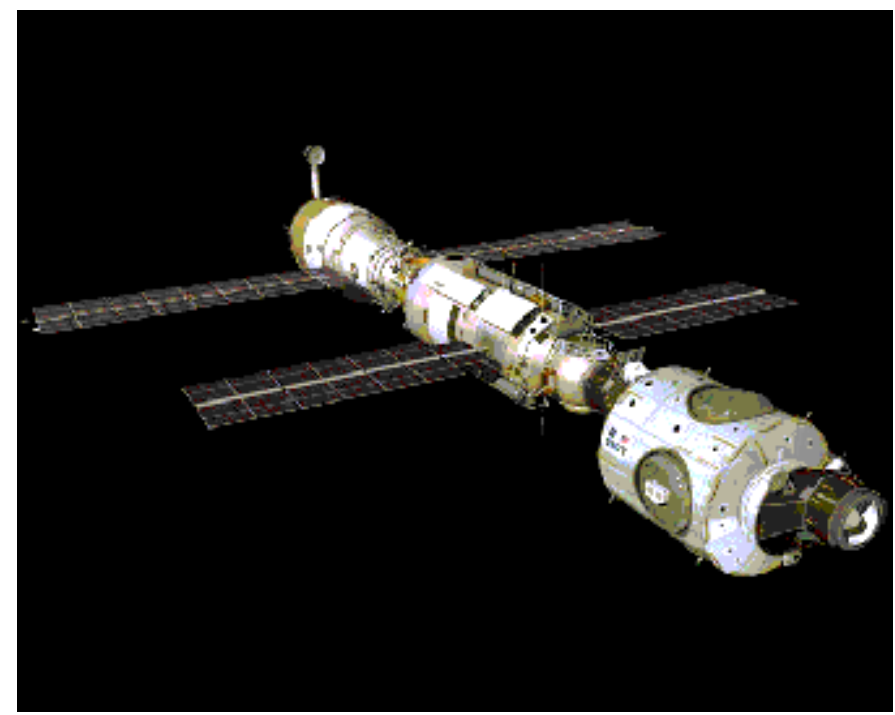

Figure 4. Configuration of ISS after flight 2A.2B

is included in an EVA.. The incident also confirms the value of reducing risk to EVA operability by conducting EVA fit checks and flowing the results into EVA operations.

The EVA community was also requested to come up with a contingency plan for the stowage of the OTD. Photos from 2A.1 showed the OTD was not fully seated into the Worksite Interface (WIF) it was mounted to. The concern was the hardware or the WIF could be damaged. Research showed the OTD could not be stowed overnight in the Middeck or Spacehab due to weight constraints. Options for tying the OTD to Node 1 with gap spanners and Equipment ties were explored in the Neutral Buoyancy Lab (NBL) in Houston as the crew slept. The plan that was worked out was that if the OTD could not be mounted properly to the WIF, to cut the EVA short by 2 hours, bag the ends of the OTD, and stow it on Node 1 using Velcro straps. The re-installation of the OTD in the original WIF socket was successfully completed by EVA crewmembers. Though the contingencies were not used, the integrated results of Shuttle, ISS design and NBL training provided a good trial run in communications. Boeing designers assured that $\mathrm{CAD}$ trained personnel were available to assist in analysis of stowage scenarios for kinematic fit and function.

\section{FLIGHT 2A.2B SPACEHAB LOGISTICS}

STS-106 lifted off on September 8, 2000 with a crew of seven. The mission was a total of eleven days, including seven docked days. The docked days consisted on 1 EVA day. The Space Station consisted of the Russian Progress 1 vehicle, Service Module, FGB, and the US Node Unity (see Figure 4). The shuttle docked to PMA2 located on the US Node. The main objectives of the overall flight were to carry internal logistics and resupply cargo for station outfitting. In addition, the crew carried out logistics transfers for arrival of the first station crew. The main objectives of the one scheduled EVA are shown in Table 3.

Table 3. Summary of EVA on STS-106 Flight 2A.2B

\begin{tabular}{|c|c|}
\hline EVA 1 & 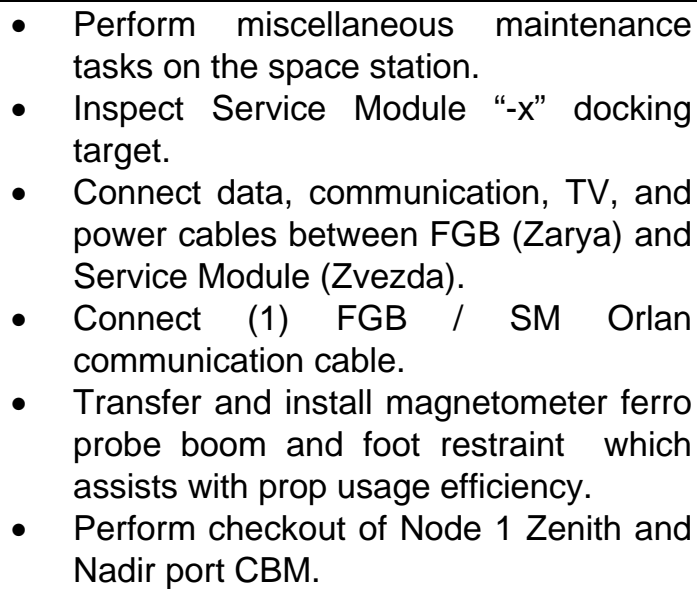 \\
\hline
\end{tabular}

The EVA lasted 6 hours and 14 minutes. The only anomaly noted during the EVA was that a few small pieces of EVA equipment, including wire ties and a connector cover, were suspected to have inadvertently come free from the ISS. Lessons learned included more training on object restraint, reexamining hardware to assure it could be confidently constrained, and contingencies for loss of items.

The other difficulty the crew faced, along with the personnel on the ground, was the lack of video downlink that made monitoring IVA ops difficult. No video was available during Orlan Rack Relocation. In spite this fact, the crew accomplished all mission objectives successfully and touched down on September 20, 2000.

\section{FLIGHT 3A INTEGRATED TRUSS STRUCTURE Z1}

STS-92 lifted off on October 11, 2000 with a crew of seven. The mission was a total of thirteen days. This included 4 EVA days. The Space Station consisted of the Russian Progress 1 vehicle, Service Module, FGB, and the US Node Unity, PMA 1 and 2. The main 
objective of STS-92 was to deliver Z1 and PMA 3 to the International Space Station. It also delivered a Ku-band Communications system and Control Moment Gyros.

Support of flight $3 \mathrm{~A}$, as with most of the missions, started before the launch. The EVA Failure Workaround Crib sheet, was developed prior to flight. The crib sheet includes short pre-defined EVA workarounds to supplement longer anomaly resolution plans covering EVA workarounds. The crib sheet covered each EVA task planned in the four EVA days on this mission. This was a major effort that should have been started a month or two prior to the mission. The crib sheet was modified and updated to include all of the inputs gathered.

In the time leading up to $3 \mathrm{~A}$, the contractor and NASA worked closely together. In a number of cases, it was found that changes to tool settings were needed on specific EVA bolts to reduce the probability of on-orbit failure. The lesson learned was that complete data for bolt torques is needed form the hardware supplier.

Table 4. Summary of EVA on STS-92 Flight 3A

\begin{tabular}{|c|c|}
\hline EVA 1 & $\begin{array}{l}\text { - } \text { Connect Z1 Umbilicals } \\
\text { - SASA Relocation } \\
\text { - Space to Ground Antenna (SGANT) } \\
\text { Dish Install and Boom Deploy } \\
\text { - Port External Tool Stowage Device } \\
\text { (ETSD) Install }\end{array}$ \\
\hline EVA 2 & $\begin{array}{lll}\text { - } & \text { PMA } 3 \text { release from SLP } \\
\text { - } & \text { Circuit Interrupt Device (CIDs) } \\
& \text { Relocation } \\
\text { - } & \text { PMA } 3 \text { Berthing } \\
\text { - } & \text { Connect PMA } 3 \text { Umbilicals }\end{array}$ \\
\hline EVA 3 & $\begin{array}{ll}\text { - } & \text { Final Z1 Umbilicals } \\
\text { - } & \text { Stbd ETSD Install } \\
\text { - } & \text { Final PMA } 3 \text { Umbilicals } \\
\text { - } & \text { Z1 Keel Relocate }\end{array}$ \\
\hline EVA 4 & $\begin{array}{ll}\text { - } & \text { Z1 FRGF Relocate } \\
\text { - } & \text { Z1 Tray Deploy } \\
\text { - } & \text { 4A APFR Relocation }\end{array}$ \\
\hline
\end{tabular}

Nominal torque data are used to develop EVA procedures. The nominal, expected data also serves as a diagnostic tool to recognize potential problems (e.g. galling) as they arise. Data on torque levels where damage occurs was also necessary. The temptation to set a power tool at it's highest setting to release a bolt can lead to shearing off a bolt head completely if a problem occurs. With bolt damage torque levels understood, the tools can be set to assure no damage is done. If the expected torque does not produce the expected result, the ground and flight crew can evaluate the situation before pushing to torques which could damage hardware. The hunger for this EVA torque data would increase as the assembly flights grew closer together.
On EVA Day 1, during the setup for the Ku Boom deploy, the Adjustable Portable Food Restraint (APFR) would not fully engage in side-mounted WIF Z1-21. The team began looking at alternate WIFs and APFR settings using graphical analysis on CAD models of the flight hardware. It was determined that side-mounted WIFs Z1-05 and Z1-06 have a nominal overhang of 0.25 " and a minimum overhang of 0.188 ", unlike Z1-01, Z1-04, Z1-21, and Z122 , which are flush mounted. A thermal shield added late to the APFR had bolts that protruded and interfered with the installation into some WIFs. During the planning shifts, the team received drawings of the APFR load alleviator thermal shroud and fasteners. EV\&CS analyzed the fit between the APFR and the side-mounted WIF. For a flush side-mounted WIF, the thermal shroud bolts definitely interfere. All remaining $3 \mathrm{~A}$ tasks and all planned 4A tasks were examined using side-mounted WIFs. They also investigated removing select fasteners to allow some clocking angles to be installed in flush side-mounted WIFs. Here the philosophy of EVA fit checks fell short since the APFR used to fit check the WIFs before flight did not include the thermal shield. The lesson learned both affirms the importance of doing EVA fit checks on flight hardware and assuring those fit checks are done with the configuration of hardware that will fly.

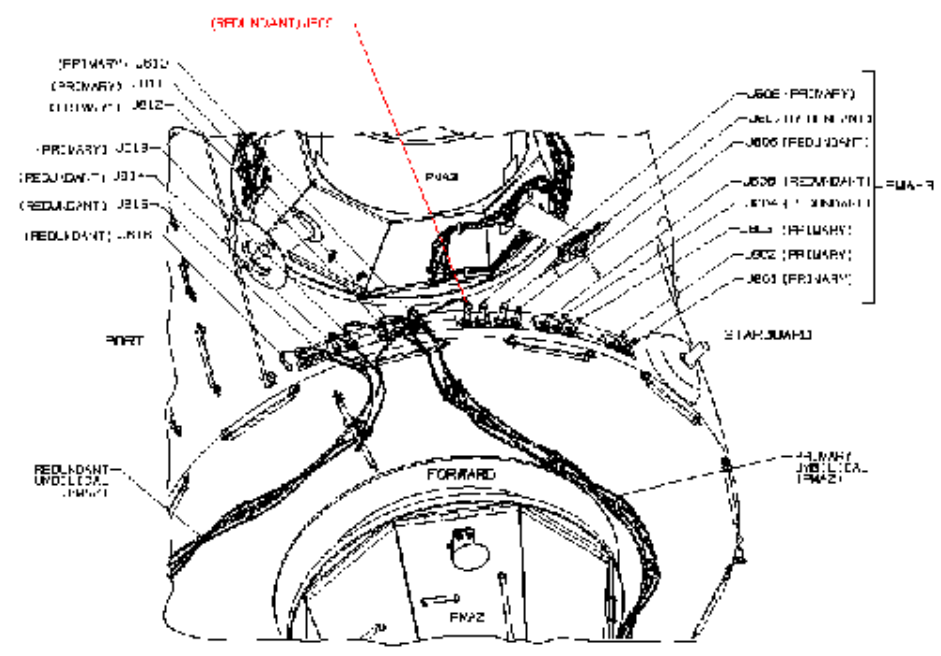

Figure 5. Flight $3 \mathrm{~A}$ umbilical connections

Z1 to Node 1 String 2 Umbilicals went well until the last cable, P139 to J639, could not be reached from the SRMS by EV2. EV1 was able to free-float the connection, but with some difficulty. Training had not shown that the RMS based restraint didn't provide access. If it had, the free-float access could have been trained for.

During the Final PMA 3 umbilical task, the P607 to J607 electrical connection worked properly (see Figure 5); however, the connection of connector P609 to jack J609 failed. Due to the work on the overnight shift, everyone knew there would be no impact if the P609 to J609 failed. 
The connector was left almost in soft-dock, the 609 cable was EVA wire tied to the 608 cable, and the thermal bootie was installed to cover the connector.

The planning shifts continued to work Flight Releasable Grapple Fixture (FRGF) Contingencies after EVA 3. A number of FRGF stowage options were discussed. The FRGF release from the launch position required a higher torque on at least one bolt. Then the shear pins exhibited minor sticking, but EV4 was able to free the FRGF with a little extra effort. The FRGF stowage went quick and easy. A relief, based on many NBL runs exhibiting difficulties with this interface. Here the training and preparation for the flight paid off in resolving this problem.

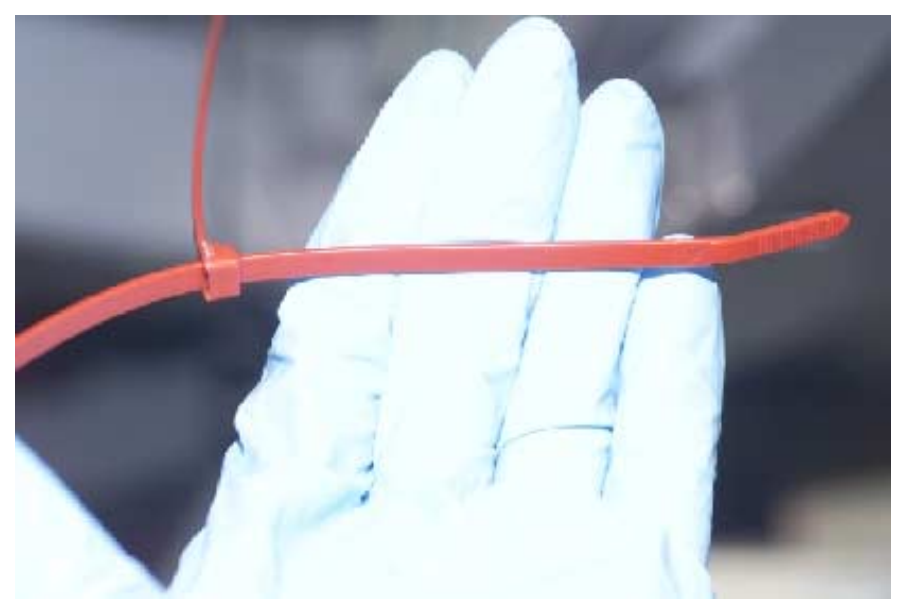

Figure 6. Wire Ties used during flight $3 \mathrm{~A}$

The "bow tie" (tray launch restraint) stowage presented several difficulties. The first problem was that the bow tie pin was difficult to install because the holes needed to be aligned, rather than against a hard-stop. The alignment mark was difficult to use on-orbit. The second problem was the zip ties fell apart.(see Figure 6) The crew was able to re-fasten three of the four zip ties and cinch them down. They did not have a high degree of confidence that the zip ties would hold, so they used an adjustable equipment tether to cinch down the bow tie. The bow tie needed to be restrained, to make the SVS targets mounted there accurate for the P6 to $\mathrm{Z1}$ mating on $4 \mathrm{~A}$, and for the PMA 2 to Z1 mating on 5A.

\section{FLIGHT 4A INTEGRATED TRUSS STRUCTURE P6}

STS-97 lifted off on November 30, 2000 with a crew of five. The mission was a total of eleven days, including seven docked days. ISS was staffed by its first resident crew. The docked days consisted on 3 EVA day, and 3 IVA days. The Space Station consisted of the Russian Progress 1 vehicle, Service Module, FGB, the US Node Unity, Z1 Truss segment, and PMA3 which provides a second docking port for the space shuttle (see Figure 7). The shuttle docked to PMA2 located on the US Node. The main objectives of STS-97 was to build and enhance the capabilities of the International Space Station. It delivered the first set of U.S. Solar Arrays and Batteries. In addition, it also delivered a set radiators to provide cooling. The STS-97 crew conducted three space walks to attach and unfurl the 73 meter (240 foot) solar arrays. A communications systems for voice and telemetry (SBand) was also installed. The main objectives of the one scheduled EVA are shown in Table 4.

The STS-97 mission, with 3 EVAs, was essentially $100 \%$ successful. During the mission, two significant ISS mission success mechanisms (Solar Array Blanket Box (SABB) tensioning mechanism, and Beta Gimbal Assembly 4-bar latching mechanism) had failures. But the EVA crew was able to perform repair operations real time and accomplished the tasks as planned.

While the crew was trying the release the Starboard BGA launch restraints, they found the 4-bar automatic spring deployment for latching did not occur. With manual deployment the crew was only able to achieve 2 of 4 latching mechanisms. Planned EVA contingency procedures to assist the 4-bar deployment with the Payload Retention Device (PRD) was then attempted. PRD deployment assist did achieve locking for 3 of 4

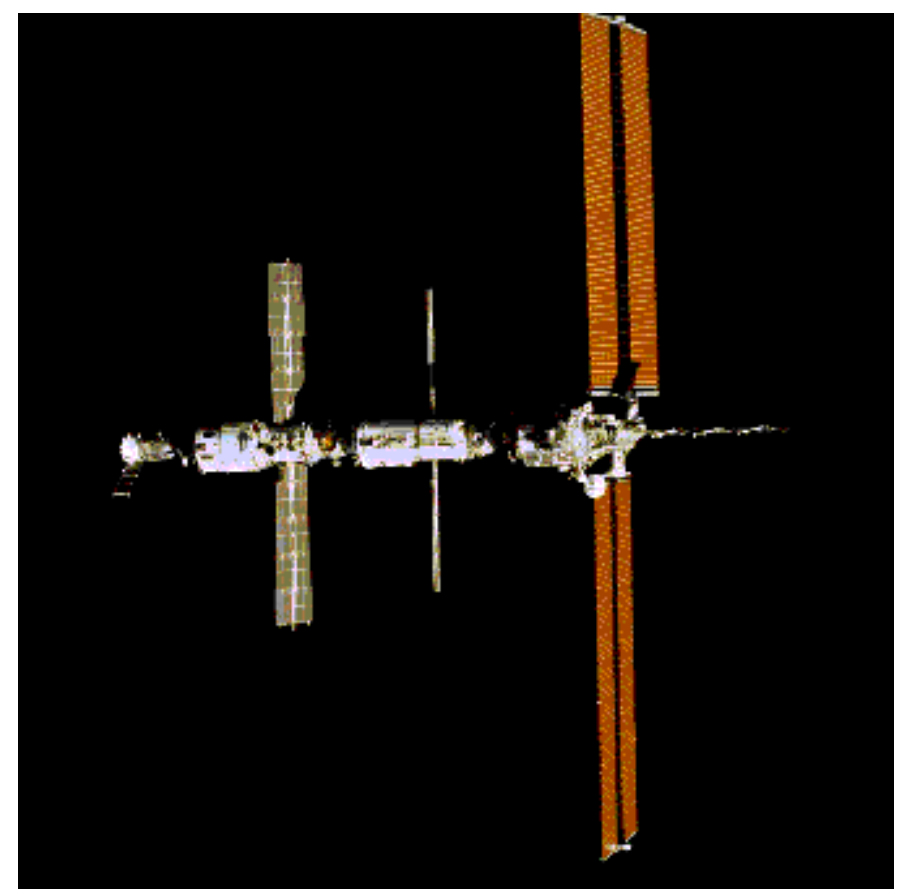

Figure 7. ISS Configuration, flight 4A.

latching mechanisms. Having an EVA back-up to automatically deployed hardware was key to mission success in this case. The spring that should have deployed the beta gimbals did not perform as designed and planned EVA contingencies completed the tasks. This shows the value of having EVA capability - consider 
if this capability were available to fully open the high gain antenna on the Galileo spacecraft.

Near the end of EVA 1 while the EVA Crew was into sortie cleanup, the Solar Array Wings (SAW) were to be unlatched and deployed via IVA commanding. Starboard SAW blanket box unlatching was IVA commanded and successfully completed. During starboard SAW mast deployment, the accordion folded solar panels showed signs of the panels sticking together. As the mast deployment continued, the sticking solar panel unfolded with a more vigorous than expected motion causing a rippling motion/force to cascade up and down the partially deployed solar blanket. As the wave in the blanket contacted the lower blanket box the SABB tensioning cable visually appeared to be in a nonstandard slack configuration. The EVA Crew was not asked to perform any other SAW contingency operations to assist in SAW deployment before the end of EVA 1.

Table 5. Summary of EVA on STS-97 Flight 4A

\begin{tabular}{|c|c|}
\hline EVA1 & $\begin{array}{l}\text { - Attached P6 Integrated Truss Structure } \\
\text { to the Z1 Truss, which was delivered to } \\
\text { the station on STS-92 (Flight 3A). } \\
\text { - Prepared the solar arrays and radiators } \\
\text { for deployment. }\end{array}$ \\
\hline EVA2 & $\begin{array}{l}\text { - Configured the space station for use of } \\
\text { the power from P6. } \\
\text { - Positioned the S-band antenna for use by } \\
\text { the space station. } \\
\text { - Prepped the station for the arrival of the } \\
\text { US laboratory on Flight 5A. }\end{array}$ \\
\hline EVA3 & $\begin{array}{l}\text { - Positioned the Floating Potential Probe } \\
\text { (FPP) to measure the plasma field } \\
\text { surrounding the space station following } \\
\text { the activation of the solar. } \\
\text { - Arrays, and help determine the } \\
\text { effectiveness of the plasma contactor } \\
\text { unit. } \\
\text { - Performed repair work to increase } \\
\text { tension in the starboard solar array } \\
\text { blankets that did not stretch out } \\
\text { completely during deployment. }\end{array}$ \\
\hline
\end{tabular}

An anomaly resolution team was immediately formed in the Houston to address the SABB failure. As part of determining the problem with the SAW a Team of EVA engineers and a crew member were sent to Lockheed Martin in Sunnyvale, California, to evaluate the failure modes on a future Flight SABB. The decision was made to survey the SABB problem on EVA 2 and prepare EVA procedures to fix the problem $n$ EVA 3.

Between EVA 2 and EVA 3 the SABB anomaly resolution team was continuing to plan the fix for the Starboard SAW tensioning mechanisms. A video of the proposed re-spooling of the tensioning cable was sent up to the
Table 6. Summary of EVA on STS-98 Flight 5A

\begin{tabular}{|l|ll|}
\hline EVA1 & $\bullet$ & Secure PMA 2 to Z1 to make room for \\
& the LAB. \\
& $\bullet$ & Disconnect LTA heater umbilicals. \\
& $\begin{array}{l}\text { Connect Lab to Node } 1 \text { LTA heater } \\
\text { umbilicals. }\end{array}$ \\
\hline EVA2 & $\bullet$ & Connect Z1 to Lab fluid QDs. \\
& $\bullet$ & Release PMA 2 from Z1 and relocate to \\
& Lab. \\
\hline EVA3 & $\bullet$ & Install PCA vent, PDGF and VSC. \\
& $\bullet$ & Transfer spare SASA. \\
& $\bullet$ & Connect PMA 2 to Lab umbilicals. \\
\end{tabular}

Crew for familiarization and discussion. EVA procedures were developed and uplinked in a flight note prior to EVA 3. SABB tension mechanism repair, consisted of respooling the tensioning cables onto the tensioning reels and was successful on the Starboard SABB. The Starboard SAW was then latched and tensioned with the Crew watching as the mechanism operated. As with the beta gimbal deployment, EVA operability again saved the mission. Without the EVA fix, the solar array would not have been able to sustain shuttle docking loads and would have had to be jettisoned.

Over all the STS-97 mission was a complete success. All primary and secondary mission objectives were successfully accomplished. The P6 Photovoltaic Module is performing as expected and providing the ISS with more than 20 Kilowatts of power. The resolution of the SABB in-flight anomaly, was solved by NASA, Boeing, and support contractors working hand-in-hand to identify repair concepts and develop EVA procedures. This mission was dominated by the work put in by the Mission Support Teams to repair the SABB tensioning mechanism, however, all other mission objectives that had their own little problem and workarounds were also handled in a thorough and expeditious manner.

\section{FLIGHT 5A DESTINY LABORATORY MODULE}

STS-98 lifted off on February 7, 2001 with a crew of five. The mission was a total of eleven days, including seven docked days, which was staffed by its first resident crew. The docked days consisted of 3 EVA days, and 4 IVA days. The Space Station consisted of the Russian Progress 1 vehicle, Service Module, FGB, and the US Node Unity, PMA 1, 2, and 3 , and Z1. The main objective of STS-98 was to deliver the U.S. Laboratory Module to the International Space Station. It also delivered a spare SASA. The STS-98 crew conducted three space walks to complete tasks like transferring the spare SASA, relocating PMA 2, and connecting PMA 2 to Lab umbilicals. The main objectives of the scheduled EVAs are shown in Table 5. 
Before the first EVA, EV\&CS were working 2 major issues: the EVA workarounds crib sheet and S-band Antenna Subassembly (SASA) return. SASA was the major issue. Questions of torque values and 5 or 6 fasteners needed for return were raised in case the SASA could not be released.

During EVA 1, PMA 2 was successfully relocated to Z1 and the Lab was mated and pressurized. While venting M7, during the Z1 to Lab fluid quick disconnect (QD) task, EV2 was sprayed with ammonia from a fluid connector with its valve stuck partially open. There was also trouble with the caps on the male side of the QDs, possibly because ice crystals were present. The crew was told that the caps were not required, so don't waste time trying to put them back on.

During EVA 2, PMA 2 was mated to the Lab, but the bail on connector P613 was broken. This problem was worked by EV\&CS planning shifts. The PCA vent task was skipped to complete the PDGF task. Anomaly resolution plans written for this task did not conceive of this particular problem.

During EVA 3, the 100th EVA, the spare SASA was successfully relocated, but an o-ring around connector P4 came loose. EV\&CS worked on getting the crew to bring the o-ring back for inspection rather than trash it. EV2 also finished up the Z1 to Lab connections. He indicated that he had better positioning this time after PMA 2 had been moved.

Overall, the STS-98 mission, with 3 EVAs, was successful. The Space Station is now outfitted with the U. S. Laboratory, which will be the center of all research on the station.

\section{FLIGHT 5A.1 FIRST MULTI-PURPOSE LOGISTICS MODULE (MPLM) FLIGHT}

STS-102 lifted off on March 8, 2001 with a crew of seven. The mission was a total of eleven days, including eight docked days. The docked days consisted on 2 EVA days, and 5 IVA days. The Space Station consisted of the Russian Progress 1 vehicle, Service Module, FGB, the US Node Unity, Z1 Truss segment, and PMA3, P6 truss segment, and the US Laboratory module. The shuttle docked to PMA2 located on the US Lab module.

The main objectives of STS-102 was to bring the second resident crew, Expedition Two, to the station: Yury Usachev, James Voss and Susan Helms and returns the first expedition crew back to Earth after four and half months. This flight truly lives up to the name Space Transportation System (STS). STS-102 also provided logistics and resupply for the expedition crew and also carried equipment to assist in outfitting of the U.S. Laboratory Module in the Italian-built MPLM named
Leonardo. The main objectives of the one scheduled EVA are shown in Table 6.

Table 7. Summary of EVA on STS-102 Flight 5A.1

\begin{tabular}{|c|c|}
\hline EVA1 & $\begin{array}{l}\text { - Relocating Pressurized Mating Adapter } 3 \\
\text { from the Unity Node electrical cables. } \\
\text { The arm would follow this by moving } \\
\text { PMA3 from Node } 1 \text { Nadir to Node } 1 \text { Port } \\
\text { using the shuttle Remote Manipulator } \\
\text { System (RMS). } \\
\text { - Remove the early communications } \\
\text { (ECOMM) antenna. } \\
\text { Install the Lab Cradle Assembly (LCA) } \\
\text { rigid umbilical installation. } \\
\text { Install rigid umbilicals on the US } \\
\text { Laboratory. }\end{array}$ \\
\hline EVA2 & $\begin{array}{l}\text { - Install the external stowage platform } \\
\text { (ESP). } \\
\text { Deliver a replacement Pump Flow } \\
\text { Control System (PFCS). }\end{array}$ \\
\hline
\end{tabular}

The MPLM was berthed to ISS Node 1 Nadir location using the shuttle RMS. This berthing then followed with Intra-vehicular activities (IVA) to outfit the US lab including the following:

- Transfer and install DDCU racks 1 \& 2

- Transfer and install Avionics, Mobile Servicing System (MSS) 1 \& 2

- Install Crew Health Care System (CheCS) racks

- Transfer MPLM soft stowage items

- Transfer ISS return items in shuttle middeck

The STS-102 mission, with 2 EVAs, was very successful and all subsystems performed as expected. The EVA translation paths and dedicated work sites also performed as expected.

Looking ahead to future missions, a lesson learned from this mission was to try to have more audio and video during IVA activities. More interactive communication of ongoing IVA activities by the crew, will allow more effective support from the ground to the crew during this activities. There is video transmission from stationary cameras, but without a camera that sees more of what the crew is actually seeing makes it difficult to troubleshoot and aid the crew if an anomaly situation were to arise.

\section{FLIGHT 6A SPACE STATION REMOTE MANIPULATOR SYSTEM}

STS-100 is scheduled to lift off on April 19, 2001, with a crew of seven. The mission will last a total of eleven days, including 2 EVA days. The main objective of STS100 will be to deliver and deploy the SSRMS or Space Station Remote Manipulator System. It will also deliver the Rafaello Multi-Purpose Logistics Module (MPLM) for Lab outfitting and an Ultra High Frequency (UHF) antenna. 
Table 8. EVA Summary for STS-100 Flight 6A

\begin{tabular}{|l|ll|}
\hline EVA1 & $\bullet$ & Flight Support Equipment Grapple \\
& Fixture (FSEGF) cable connect to \\
& provide and keep-alive power to SSRMS. \\
& $\bullet$ & UHF Antenna Install. \\
& SSRMS deployment. \\
\hline EVA2 & $\bullet$ & J400 panel reconfiguration to remove \\
& power from FSEGF and connect power \\
& to Lab power. \\
& Data Grapple Fixture (PDGF) FSEGF \\
& cable disconnect from Lab J300 panel \\
& LCA. \\
& Starboard ECOMM Antenna removal. \\
& UHF antenna connect. \\
Digital Converter Signal Unit (DCSU) \\
Install.
\end{tabular}

The Canadian-built SSRMS is needed to perform assembly operations on later flights. The Italian-built MPLM will carry six system racks and two storage racks for the U.S. Lab. The UHF antenna will provide spaceto-space communications capability for U.S.-based EVAs. The main objectives of the scheduled EVAs are shown in Table 7.

If the DCSU install is performed on EVA 2, it will require the SSRMS to powerup to operational, demate SLP, and maneuver away to avoid interference with SRMS translation to DCSU install position. Otherwise, it will be performed on the unscheduled EVA 3.

In between the EVA days, there are SRMS operations going on. During the MPLM Install on Node 1 nadir with SRMS, there will be a clearance of less than $1 \mathrm{ft}$ between SRMS and SSRMS.

\section{FLIGHT 7A JOINT AIRLOCK}

STS-104 is scheduled to lift off on June 8, 2001. The mission will include 3 EVA days. The main objective of STS-104 will be to deliver the Joint Airlock to the International Space Station. The airlock will provide station-based EVA capability for both U.S. and Russian spacesuits. The installation of the airlock will involve some of the most complex assembly work of the ISS program. The Extra vehicular activities to be performed are shown on Table 8.

Connecting the O2/N2 umbilicals to the Airlock provides a high pressure $\mathrm{O} 2$ or N2 gas supply for consumables during Airlock and EMU servicing operations. The EVA connection of these tanks is unprecedented. Failure to connect these umbilicals will prevent re-supply of consumed $\mathrm{O} 2$ or N2 during Airlock and EMU servicing operations.
Table 9 EVA Summary for STS-104 Flight 7A

\begin{tabular}{|l|ll|}
\hline EVA 1 & $\bullet$ & PAD/PFR install. \\
& $\bullet$ & Towel Bar install. \\
& $\bullet$ & PCBM cover removal. \\
& $\bullet$ & LTA jumper removal in the payload bay. \\
EVA 2 & $\bullet$ & ONTO1 (O2 N2 Tank ORU) and ONTO \\
& $\begin{array}{l}4 \text { install. } \\
\text { Airlock GF and trunnion pin cover install. }\end{array}$ \\
\hline EVA 3 & $\bullet$ & $\begin{array}{l}\text { ONTO 2 and ONTO } 3 \text { install. Orlan UHF } \\
\text { antenna cable and Airlock handrail } \\
\text { install. }\end{array}$ \\
&
\end{tabular}

\section{CONCLUSIONS}

In rapid succession, flights $3 A, 4 A, 5 A, 5 a .1$, have and flights $6 a$ and $7 a$ will take the station from a small outpost to a world class research facility, the largest and most powerful spacecraft ever flown. EVA operations have been key to assembly. In executing these EVA's, we learn lessons that we must immediately apply to the wall of EVA's to come in the next 3 years. As more diverse teams get involved, including not only various US contractors, but also representatives from different countries, it becomes very helpful to have all the teams present before, during, and after the mission. As the launch frequency increases, the amount of work required in preparation for these missions will increase significantly to continually achieve mission success.

The missions thus far have shown NASA's EVA team and the international partners have the capability to accomplish nominal assembly with hard earned ease and meet the unexpected with teamwork and resourcefulness. 


\section{DEFINITIONS}

$\begin{array}{ll}\text { APFR } & \text { Adjustable Portable Foot Restraint } \\ \text { CBM } & \text { Common Berthing Mechanisms } \\ \text { CheCS } & \text { Crew Health Care System } \\ \text { CIDS } & \text { Circuit Interrupt Device } \\ \text { DDCU } & \text { DC-to-DC Conversion Units } \\ \text { DCSU } & \text { Digital Converter Signal Unit } \\ \text { ECOMM } & \text { Early communications } \\ \text { ESP } & \text { External Stowage Platform } \\ \text { ETSD } & \text { External Tool Storage Device } \\ \text { EV\&CS } & \text { Extravehicular \& Crew Systems } \\ \text { EVA } & \text { Extravehicular Activity } \\ \text { FRGF } & \text { Flight Releasable Grapple Fixture } \\ \text { FSEGF } & \text { Flight Support Equipment Grapple Fixture } \\ \text { FPP } & \text { Floating Potential Probe } \\ \text { FGB } & \text { Functional Cargo Block } \\ \text { ISS } & \text { International Space Station } \\ \text { LCA } & \text { Lab Cradle Assembly } \\ \text { MBM } & \text { Manual Berthing Module } \\ \text { MPLM } & \text { Mini Pressurized Logistics Module } \\ \text { MER } & \text { Mission Evaluation Room } \\ \text { MOD } & \text { Mission Operations Directorate } \\ \text { MSS } & \text { Mobile Servicing System } \\ \text { MBL } & \text { Neutral Buoyancy Lab } \\ \text { OIH } & \text { orbit installed handrail } \\ \text { OTD } & \text { Orbit Replaceable Unit Transfer Device } \\ \text { PRD } & \text { Payload Retention Device } \\ \text { PDGF } & \text { Power Data Grapple Fixture } \\ \text { PMA } & \text { Pressurized Mating Adapter } \\ \text { PFCS } & \text { Pump Flow Control System } \\ \text { RMS } & \text { Remote Manipulator System } \\ & \end{array}$

$\begin{array}{ll}\text { QD } & \text { Quick Disconnect } \\ \text { SABB } & \text { Solar Array Blanket Box } \\ \text { SASA } & \text { S-band Antenna Subassembly } \\ \text { SAW } & \text { Solar Array Wings } \\ \text { SGANT } & \text { Space To Ground Antenna } \\ \text { SSRMS } & \text { Space Station Remote Manipulator System } \\ \text { STS } & \text { Space Transportation System } \\ \text { SVS } & \text { Space Vision System } \\ \text { UHF } & \text { Ultra High Frequency } \\ \text { WIF } & \text { Worksite Interface }\end{array}$

\section{REFERENCES}

1. Craig Covault. 2001. "EVA Challenges Abound as ISS Buildup Accelerates." Aviation Week. March 21.

2. David E. Anderson, "EVA Worksite Analysis - Use of Computer Analysis for EVA Operational Development and Execution", MDC 98H1358, IAA98-IAA.10.1.04, Presented at the 49th International Astronautical Federation Congress, Melbourne, Australia, 1 October 1998.

3. Craig Covault. 2001. "Solar Array Problems Mobilize NASA/Contractor ISS Team." Aviation Week. December 11.

\section{CONTACT}

David E. Anderson, The Boeing Company, 5301 Bolsa, Mail Code H017-D107 Huntington Beach, CA 92647. (714) 896-3311 ext. 7-1313. E-mail: david.anderson@alum.mit.edu 